\title{
Comments on "The Efficacy of 12 Weeks of Sofosbuvir, Daclatasvir, and Ribavirin in Treating Hepatitis C Patients with Cirrhosis, Genotypes 1 and 3"
}

\author{
Babak Sayad, ${ }^{1,}{ }^{*}$ Fatemeh Norooznezhad, ${ }^{1}$ and Alireza Farokhi ${ }^{1}$ \\ ${ }^{1}$ Liver Diseases Research Center, Kermanshah University of Medical Sciences, Iran \\ "Corresponding author: Babak Sayad, Liver Diseases Research Center, Kermanshah University of Medical Sciences, Iran, E-mail: babaksayad@yahoo.com
}

Received 2017 February 13; Accepted 2017 March 01.

\section{Dear Editor,}

We are greatly fascinated by the article entitled "The efficacy of 12 weeks of sofosbuvir, daclatasvir, and ribavirin in treating hepatitis $C$ patients with cirrhosis, genotypes 1 and 3" (1). It is a great honor that Sovodak (a fixed-dose combination of sofosbuvir $400 \mathrm{mg}$ and daclatasvir $60 \mathrm{mg}$ in a single pill), formulated in Iran, has shown such great effectiveness in the treatment of patients with chronic HCV infection and cirrhosis. The effort to achieve sustained virologic response (SVR) in these patients has been reported to be $92 \%$, which is higher than the rates reported in similar studies.

The authors have suggested Sovodak for its ease of use as a single pill per day, its effectiveness as a pangenotypic drug, and its use as the first choice of treatment for all HCV patients. They have also mentioned the lowest level of drug interactions between this combination and antiretroviral drugs, which makes it a good choice for HIV/HCV-coinfected patients (1).

Although the fixed-dose combination of sofosbuvir $400 \mathrm{mg}$ and daclatasvir $60 \mathrm{mg}$ can be used in most patients with chronic HCV infection of different genotypes $(2,3)$, it is crucial to adjust daclatasvir dose in patients with HIV coinfection, receiving antiretroviral drugs $(4,5)$. In fact, treatment of HIV/HCV-coinfected patients is of great intricacy (6), as they are more exposed to liver-related morbidity and mortality, as well as nonhepatic organ dysfunction in comparison to HCV-monoinfected patients (2).

On the other hand, HCV drug interactions with antiretroviral drugs make the treatment process even more complicated. Among Direct Acting Antiviral (DAA)-based treatment regimens for chronic HCV infection, the combination of daclatasvir and sofosbuvir has shown manageable interactions with anti-HIV drugs (7). Given the fact that daclatasvir is a substrate of CYP3A4 and that regimens containing etravirine and efavirenz decrease daclatasvir exposure through CYP3A4 induction, it seems necessary to increase the dose of daclatasvir to $90 \mathrm{mg}$ daily in order to minimize the drug interactions $(2,3,8)$.
Moreover, concomitant prescription of daclatasvir with antiretroviral regimens, which contain atazanavir/ritonavir and inhibit CYP3A4, would cause a 2.1-fold increase in the area under the curve (AUC) of daclatasvir (8). Likewise, a combination of atazanavir and cobicistat exhibits the same interactions with daclatasvir. Therefore, the dose of daclatasvir should be decreased to $30 \mathrm{mg}$ daily when prescribed along with these antiretroviral drugs $(2,3,8,9)$.

Since efavirenz-containing treatment regimens are frequently prescribed for HIV-infected patients in Iran and regimens containing atazanavir and ritonavir are considered as the second line of treatment (10), simultaneous treatment of HCV infection with a fixed dose of daclatasvir in Sovodak is not recommended. Therefore, in case of using sofosbuvir plus daclatasvir in HIV/HCV-coinfected patients, it is of great necessity to use these medications separately so that daclatasvir dosage can be adjusted when needed. Fortunately, sofosbuvir $400 \mathrm{mg}$ and daclatasvir 30 and $60 \mathrm{mg}$ have been generically formulated in Iran, which facilitates the prescription of daclatasvir at doses of 30 to $90 \mathrm{mg}$ for this patient population.

\section{Acknowledgments}

The authors are immensely grateful to Dr. Hengame Namdari Tabar and Dr. Katayoun Taeri for their kind help.

\section{References}

1. Merat S, Sharifi AH, Haj-Sheykholeslami A, Poustchi H, Fattahi B, Nateghi-Baygi A, et al. The efficacy of 12 weeks of sofosbuvir, daclatasvir, and ribavirin in treating hepatitis $C$ patients with cirrhosis, genotypes1 and 3. Hepat Mon. 2016;17(1) doi:10.5812/hepatmon.44564.

2. American Association for the Study of Liver Diseases . Recommendations for Testing, Managing, and Treating Hepatitis C 2016.

3. E. A. S. L. . EASL recommendations on treatment of hepatitis C 2016.J Hepatol. 2017;66(1):153-94. doi:10.1016/j.jhep.2016.09.001.

4. Menon RM, Badri PS, Wang T, Polepally AR, Zha J, Khatri A, et al. Drugdrug interaction profile of the all-oral anti-hepatitis $C$ virus regimen of paritaprevir/ritonavir, ombitasvir, and dasabuvir. $J$ Hepatol. 2015;63(1):20-9. doi: 10.1016/j.jhep.2015.01.026. [PubMed: 25646891]. 
5. Burgess S, Partovi N, Yoshida EM, Erb SR, Azalgara VM, Hussaini T. Drug Interactions With Direct-Acting Antivirals for Hepatitis C: Implications for HIV and Transplant Patients. Ann Pharmacother. 2015;49(6):674-87. doi: 10.1177/1060028015576180. [PubMed: 25770114].

6. Martinello M, Dore GJ, Skurowski J, Bopage RI, Finlayson R, Baker $\mathrm{D}$, et al. Antiretroviral use in the Cease cohort study and implications for direct-acting antiviral therapy in human immunodeficiency virus/hepatitis C virus coinfection. Open Forum Infect Dis. 2016;3(2) doi:10.1093/ofid/ofw105.

7. Macias J, Monge P, Mancebo M, Merchante N, Neukam K, Real LM, et al. High frequency of potential interactions between direct-acting antivirals and concomitant therapy in HIV/hepatitis C virus-coinfected patients in clinical practice. HIV Med. 2016 doi: 10.1111/hiv.12471.
[PubMed: 27882706].

8. Garimella T, You X, Wang R, Huang SP, Kandoussi H, Bifano M, et al. A Review of Daclatasvir Drug-Drug Interactions. Adv Ther 2016;33(11):1867-84. doi: 10.1007/s12325-016-0407-5. [PubMed: 27664109].

9. Smolders EJ, Colbers EP, de Kanter CT, Velthoven-Graafland K, Drenth JP, Burger DM. Daclatasvir $30 \mathrm{mg} /$ day is the correct dose for patients taking atazanavir/cobicistat.JAntimicrob Chemother. 2017;72(2):486-9. doi: 10.1093/jac/dkw429. [PubMed: 27798211].

10. National protecol for evaluation of patients with HIV/AIDS and an tiretroviral treatment in adolescent and adults. Tehran, Iran: Ministry of Health and Medical Education, Deputy of Health, Center of Disease Control; 2014. 